\title{
Promoting Inclusion via Cross-group Friendship: The Mediating Role of Change in Trust and Sympathy
}

\author{
Jeanine Grütter ${ }^{1}$ \\ Luciano Gasser ${ }^{1}$ \\ Antonio Zuffianò ${ }^{2}$ \\ Bertolt Meyer $^{3}$
}

${ }^{1}$ University of Teacher Education Lucerne, Switzerland

${ }^{2}$ Liverpool Hope University, Liverpool, UK

${ }^{3}$ Chemnitz University of Technology, Germany

Conflict of Interest: The authors declare that they have no conflict of interest.

Acknowledgments: This research has been funded by the Swiss National Science Foundation [grant number: 13DPD3_124764]. The authors are grateful to the undergraduate students who assisted in the data collection and to all the teachers and students who participated in the study. 
Correspondence concerning this article should be addressed to Jeanine Grütter, Institute for Diversity in Education, University of Teacher Education, 6004 Lucerne, Switzerland. Email: jeanine.gruetter@phlu.ch, Phone: +41228 4524.

This is the accepted of an article published in Chid Development http://onlinelibrary.wiley.com/doi/10.1111/cdev.12883/full 


\begin{abstract}
To understand the conditions fostering positive outcomes of inclusive schooling, this two-wave study examined the role of individual change in trust and sympathy for adolescents' cross-group friendships and inclusive attitudes towards students with low academic achievement. Cross-group friendships, intergroup trust, intergroup sympathy, and inclusive attitudes were obtained from surveys completed by 1122 Swiss adolescents $\left(M_{\text {age } T I}\right.$ $=11.54$ years, $M_{\text {age } T 2}=12.58$ years) from 61 school classes. Results from a parallel latent change score model revealed that the number of cross-group friendships positively related to individual change in trust and sympathy; this growing trust and sympathy in turn predicted adolescents' inclusive attitudes. These findings are discussed regarding theories of intergroup contact and inclusive schooling.
\end{abstract}

Keywords: Cross-group friendship; Intergroup trust; Sympathy; Attitudes towards inclusion. 
Promoting Inclusion via Cross-group Friendship: The Mediating Role of Change in Trust and Sympathy

With the aim of creating an inclusive society for individuals from different social backgrounds and with different developmental requirements, nearly 100 countries signed the Salamanca statement requiring the implementation of policies for inclusive education (UNESCO, 1994). According to the philosophy of inclusive education, diversity among students potentially fosters interactions between individuals who are different from each other: A number of studies show that contacts between students from different social groups can enhance positive intergroup attitudes in children and adolescents (Pettigrew \& Tropp, 2006; Tropp \& Prenovost, 2008). However, this research has primarily focused on students from different ethnicities while only a few studies have investigated students with low academic achievement (for exceptions see for example Armstrong, Morris, Abraham, Ukoumunne, \& Tarrant, 2016; Cameron \& Rutland, 2006; Grütter \& Meyer, 2014). This is relatively surprising, since studying contacts between the majority group of typically developing students and their classmates with low academic achievement can help us understand how acceptance and inclusion among students can be promoted.

Regardless of the social category under investigation, the strongest positive effects of intergroup contact result from high-quality contacts, such as friendships (Pettigrew \& Tropp, 2006), as they are likely to induce positive emotions and are likely to reduce negative emotions related to the perception of the out-group (Pettigrew \& Tropp, 2008; Turner, Hewstone, \& Voci, 2007). However, to date, little is known about why cross-group friendships affect children's or adolescents' intergroup attitudes: Studies on psychological mechanisms through which children or adolescents with cross-group friends develop positive attitudes towards out-group members are scarce (Aboud \& Spears Brown, 2013). Of the few studies that tested such mechanisms in children or adolescents, most have been cross- 
sectional (for exceptions see Feddes, Noack, \& Rutland, 2009; Munniksma, Verkuyten, Flache, Stark, \& Veenstra, 2015; Swart, Hewstone, Christ, \& Voci, 2011). However, testing process assumptions with cross-sectional designs does not only have several methodological limitations (see Maxwell, Cole, \& Mitchell, 2011), but also disregards the fact that processes need time to unfold (Selig \& Preacher, 2009). In addition, as noted by Selig and Preacher (2009), "development is most often conceived of as occurring within individuals" (p. 146). Consequently, testing assumptions about developmental processes requires a specific focus on individual change.

In the present study, we addressed these research gaps by examining the role of individual change in trust and sympathy for cross-group friendships between early adolescents with and without academic difficulties. In particular, we studied whether such friendships lead to increased intergroup trust towards and sympathy for hypothetical children with low academic achievement, and whether this individual change in trust and sympathy predicts inclusive attitudes among children without academic difficulties. In contrast to earlier studies, we specifically studied the role of change in trust and sympathy because these core interpersonal emotions influence how individuals encode social situations and react to social groups (Smith \& Mackie, 2015). Thus, we assumed that adolescents who experience an increase in trust and sympathy would express more inclusive attitudes towards students with low academic achievement. Prior studies have shown that friendships represent a powerful context for the development of emotions like trust and sympathy in out-group members (Pettigrew \& Tropp, 2008; Turner et al., 2007), which can be particularly important during early adolescence, when friendships become more stable, close and intimate (Bukowski, Motzoi, \& Meyer, 2009; Newcomb \& Bagwell, 1995). Based on these developmental changes in the quality of friendship during early adolescence, this study 
examined the role of trust and sympathy in the emergence of early adolescents' inclusive intergroup attitudes.

\section{Inclusive Education and Social Participation of Students With low Academic}

\section{Achievement}

The primary goal of inclusive education is to enable every student's effective participation in society (United Nations, 2006). In Switzerland, where this study was conducted, recent policies regarding inclusive education enable the placement of students with learning difficulties in regular classrooms. Traditionally, most of these students attended small separate classes within regular schools or visited schools designed for special needs education (Grütter, Meyer, \& Glenz, 2015). In inclusive classrooms, where the regular classroom teachers hold the main responsibility for the class, students with academic difficulties may receive additional assistance from a teacher with particular skills in dealing with special educational needs (SEN). The purpose of this additional support is to facilitate the active inclusion of students with academic difficulties in classroom activities; however, recent studies have shown that their social participation may be limited. These studies indicate that these students are likely targets for bullying and victimization (Nabuzoka, 2003; Sabornie, 1994). Furthermore, low-achieving students are less accepted by classmates and less included in peer groups than children with average or high academic achievement (e.g., Bakker, \& Bosman, 2003; Grütter, et al., 2015; Vaughn, Elbaum, \& Schumm, 1996). Additionally, longitudinal studies using social network analyses have shown that adolescents' friendships are formed based on academic achievement, whereby adolescents most likely select friends with similar grades (Flashman, 2012; Shin \& Ryan, 2014). Taken together, these findings suggest that academic achievement is a central social category in the context of social participation in inclusive classrooms.

Along these lines, these prior studies emphasize that simply putting children with 
different learning needs into the same classroom is not enough to promote their social participation. Social inclusion of students with low academic achievement requires improving attitudes towards them among majority group students without higher learning needs (Bates, McCafferty, Quayle, \& McKenzie, 2015). However, attitudes towards children with intellectual disabilities or low academic achievement are generally negative (Nowicki \& Sandieson, 2002). For example, children use more negative and less positive descriptions for children with learning disabilities than for children without learning disabilities (Nowicki, 2012). Similarly, research on children's understanding of intellectual disabilities suggests that, although they express willingness to help disabled peers, they do not necessarily like to include these children into peer activities (Magiati, Dockrell, \& Logotheni, 2002).

Consequently, since students with low-academic achievement in inclusive classrooms not only represent a numerical but also a social minority group (i.e., with lower social positions), it is important to understand how inclusive intergroup attitudes emerge in order to reduce their social exclusion. A promising source of promoting such positive intergroup attitudes is intergroup contact, particularly if this contact occurs in the form of friendship (Tropp \& Prenovost, 2008).

\section{Cross-Group Friendship and Attitudes Towards the Inclusion of Students With low}

\section{Academic Achievement}

Although there is extensive literature on characteristics of social relationships of students with and without academic difficulties, less is known about whether friendships between students with and without academic difficulties may lead to changes in the orientation of the majority group of students without academic difficulties towards students with low academic achievement. Previous studies have shown that friendships between students with and without academic difficulties have a strong potential to reduce negative attitudes towards students with academic difficulties (e.g., Grütter \& Meyer, 2014). Cross- 
group friendships fulfill most of Allport's (1954) conditions for optimal intergroup contact as they are voluntary, include common goals and shared interest. These conditions (i.e., authority support, interdependence, acquaintance potential, and equal status) have the strongest effects on the development of positive intergroup attitudes among children and adolescents (Tropp \& Prenovost, 2008). In addition to the question if cross-group friendships enhance adolescents' intended inclusion, the more important question is how such friendships work. Research with adult samples indicates that social-cognitive variables (e.g., enhanced knowledge about the out-group) and affective variables (i.e., emotions) mediate the link between contact and positive attitudes (Aboud \& Spears Brown, 2013; Pettigrew \& Tropp, 2008).

\section{The Role of Intergroup Emotions in Cross-Group Friendship}

Emotions are very powerful mediators of intergroup contact and prejudice; compared to cognitive processes, emotions have revealed the highest effect sizes for the reduction of prejudice in meta-analytic reviews (Pettigrew \& Tropp, 2008). In other words, the strongest explanation for positive effects of cross-group friendship is the generation of positive affect (i.e., positive emotions) and the reduction of negative affect (i.e., negative emotions) towards out-group members. As such affective processes become particularly important during early adolescence, when friendships provide emotional security, validation and support (Bukowski et al., 2009; Newcomb \& Bagwell, 1995), this study focused on two specific emotions that may predict adolescents' development of positive intergroup attitudes: Sympathy and trust. Furthermore, previous research has highlighted the role of intergroup anxiety in cross-group interactions (Stephan \& Stephan, 1985); thus we accounted for the role of such negative emotional reactions in the development of adolescents' intergroup attitudes. We now briefly outline these three emotions.

Intergroup sympathy. Sympathy is defined as an affective response to others' emotional 
states and perspectives that is characterized by feelings of concern for another; thereby, sympathy involves the apprehension of the others' emotional state (Eisenberg, Eggum, \& Di Giunta, 2010). Unlike empathy, which is defined as an affective response that is similar to the other persons' feelings, sympathy does not necessarily involve feeling the same emotions as the other. As an other-oriented emotion, sympathy shifts the focus from the self to others and thereby enhances perspective taking. A substantial body of research has shown that sympathy is positively related to pro-social behavior (Eisenberg et al., 2010).

Sympathy likely emerges from the disclosure of personal information and reciprocal understanding that typically characterizes friendship (Pettigrew \& Tropp, 2008). Friendships are important means for adolescents to acquire such interpersonal and social skills. As individuals become more sensitive towards thoughts and feelings for their friend, their concern for their friends' well-being increases (Bukowski, 2001). Findings from a recent longitudinal study were in line with this reasoning as friendships were positively related with higher sympathy and pro-social behavior (Padilla-Walker, Fraser, Black, \& Bean, 2015). This enhanced sympathy for friends may also transfer to out-group members; in this intergroup context, sympathy has been shown to be an important and highly positive mediator of intergroup contact (Pettigrew \& Tropp, 2008). To date, however, studies investigating the role of sympathy or empathy for out-group members in children or adolescent samples are scarce (e.g., Abbott \& Cameron, 2014; Swart, Hewstone, Christ et al., 2011; Turner et al., 2007). Results from studies realized with adolescent samples have shown that cross-group friendships lead to an increase in empathy towards out-group members, and thus, result in more positive attitudes about the out-group in general (Abbott \& Cameron, 2014; Turner et al., 2007). Furthermore, a cross-sectional study showed that children without disabilities who reported intergroup contact with students with mental disabilities also reported more sympathy for hypothetical students with mental disabilities (Gasser, Malti, \& Buholzer, 
2013).

Intergroup trust. Trust is defined as a multi-dimensional construct with three bases: Reliability (i.e., if the person is keeping promises), emotional trust (i.e., not causing emotional harm, being confidential), and honesty (i.e., telling the truth, not being manipulative) (Rotenberg, 2010). Mutual trust becomes more important for relationships during middle childhood (Kahn \& Turiel, 1988) and is associated with pro-social behavior (Malti et al., 2016). Trust is important for generating interpersonal attraction: With intimacy and self-disclosure, the friendship is increasingly characterized by reciprocal trust (Rotenberg, 1986; Turner et al., 2007). Furthermore, loyalty and confidentiality, which reflect two important dimensions of trust (Rotenberg, 2010), become more important provisions of friendships during early adolescence (Newcomb \& Bagwell, 1995).

Enhanced feelings of trust may also relate to improved intergroup attitudes towards out-group members (Tam, Hewstone, Kenworthy, \& Cairns, 2009; Turner et al., 2007). This trust in out-group members is called intergroup trust and is defined as positive expectations about intentions and behaviors of the out-group towards the in-group. In this intergroup context, out-group members are perceived as reliable if they keep promises; they are perceived trustworthy if they do not cause harm to the in-group; and they are perceived as honest if they are telling the truth (Turner et al., 2010). Research on intergroup trust in children and adolescents is scarce; this research suggests that children perceive out-group members as less trustworthy compared to in-group members (Rotenberg \& Cerda, 1994). Nevertheless, cross-group friendship in early adolescents can lead to increased trust in outgroup members and results in more positive attitudes about the out-group in general because greater trust in out-group friends may transfer to the entire social group of the out-group friend. If the friend is perceived as trustworthy, it may also imply that the friends' social group can be trusted (Tam et al., 2009; Turner et al., 2007). Prior research on intergroup trust 
in adolescents has shown that cross-group friendship can elicit positive expectations about out-group members regarding their intentions and their behavior (Turner et al., 2007).

Intergroup anxiety. Intergroup anxiety refers to negative feelings about being in an unfamiliar place with out-group members. Individuals high in intergroup anxiety anticipate negative psychological (e.g., feelings of discomfort), behavioral (e.g., harm or conflicts) or evaluative (e.g., negative reactions of in-group members) consequences for themselves as a result of interacting with out-group members. Thus, adolescents with high levels of intergroup anxiety either avoid to interact with out-group members or experience interactions as less positive, as they focus on negative aspects during intergroup interactions (Stephan \& Stephan, 1985). Therefore, intergroup anxiety may negatively relate to the development of adolescents' attitudes towards the inclusion of students with low-academic achievement.

\section{The Present Study}

This study investigated the mediational effects of changes in trust and sympathy in linking cross-group friendship and attitudes towards the inclusion of students with low academic achievement. Given that the previous elaboration on trust and sympathy not only highlight their importance for cross-group friendships, but also showed that these emotions and their importance are likely to change as a function of adolescents' friendship development, we specifically examined the role of change in trust and sympathy in the emergence of early adolescents' intergroup attitudes. As emotions influence how individuals encode social situations and react to social groups (Smith \& Mackie, 2015), we hypothesized that the number of cross-group friendships would relate to an increase in intergroup trust and sympathy over a year and that this individual change would be associated with higher attitudes towards inclusion after this year. Furthermore, as children with high levels of intergroup anxiety may be less inclusive (Cameron \& Rutland, 2006), we controlled for adolescents' initial levels of intergroup anxiety. Lastly, we also controlled for age 
differences and adolescents' nationality, academic achievement, hyperactivity, emotional, and conduct problems, as these variables relate to the formation of adolescents' peer relationships (e.g., Flashman, 2012; Grütter et al., 2015; Rubin, Bukowski, \& Parker, 2006) and may influence the development of trust and sympathy, two emotions deeply rooted in adolescents' social interactions (Eisenberg et al., 2010; Malti et al., 2016). We tested our hypothesized mediational model in a longitudinal design with two waves of data. Given our focus on the developmental processes of trust and sympathy, we used latent change score modeling, as this allowed us to model intraindividual and interindividual change in sympathy and trust simultaneously.

\section{Method}

\section{Participants and Design}

Participants were assessed at two time points: First, at the end of grade 5 (between May and June 2014) and subsequently one year later, at the end of grade 6 (between May and June 2015). At the first measurement time (T1), participants were 1128 adolescents from 61 school classes in Switzerland. We excluded six students from the sample because no information about their academic achievement was available, reducing the usable sample size to 1122 adolescents $\left(50 \%\right.$ females, ages $10-14, M_{\text {age }}=11.54$ years, $\left.S D=0.54\right)$. At the second measurement time (T2), there were 941 adolescents (49\% females) from 54 school classes (ages $11-15, M_{\text {age }}=12.58$ years, $\left.S D=0.56\right)$. At both time points $(\mathrm{T} 1 \& \mathrm{~T} 2)$, all the students attended inclusive classrooms; thus, at least one student in this inclusive classroom received additional support from a teacher with special competencies in dealing with SEN. Twentytwo percent of participants were classified as having low academic achievement (more details on how students with low academic achievement were identified and information regarding this subsample are given below). 
Written information was provided for parents in the four official languages of Switzerland; this information was also translated into the most frequently spoken foreign languages. Parents' informed consent was obtained, whereby at T1 and at T2 only $1 \%$ of the parents refused their consent. Furthermore, oral assent of the adolescents was requested and they were able to withdraw from the study any time. Parents, students and teachers were informed that this study addressed the development of social relationships. All the participants filled in a questionnaire during 15-20 minutes, whereby five trained research assistants guided them through the study. Meanwhile, class teachers filled in a questionnaire on their students' academic performance and social skills. After completing the survey, adolescents received a small gift (i.e., a magazine) and were dismissed.

Among the adolescent participants that participated at both time points, 39\% were of non-Swiss nationality (Kosovo: 21\%, Portugal: 12\%, Serbia: 10\%, Germany: 9\%, Italy: 7\%, Macedonia: 6\%, Turkey: 6\%, other nationalities: $31 \%$ ). Similarly to other recent studies in Switzerland (e.g., Gasser, Malti, \& Buholzer 2014), parents' educational level was estimated based on governmental data about the school community where the adolescents lived in. This information is provided by the Swiss Federal Statistical Office. At T1, approximately, 24\% of the parents completed obligatory school, $50 \%$ completed post-secondary diploma and $20 \%$ achieved a bachelor's degree or higher. Information regarding sample attrition and missing data analysis are reported in the online appendix S0.

\section{Measures}

Descriptive statistics, correlations, and reliability coefficients of the study variables are shown in Table S1 in the online appendix.

Identification of students with low academic achievement. To assess academic achievement, teachers rated each student on three items (e.g., "Performing academically at grade level”, "Able to read grade level material and answer questions about what he or she 
has read," "Able to solve grade level math problems"), which were responded on a five-point response scale $(1=$ almost always to $5=$ almost never $)($ Hughes, Dyer, Luo, \& Kwok, 2009). The reliability of this scale was $\alpha=.94$ (at T1 \& T2) and the scale had a high stability across the two time points, $r=.89(p<.01)$. Students who scored in the lowest $20 \%$ of the sample in their academic achievement were classified as low achieving students $(n=245)$ and represented the out-group in our study.

The literature suggests that students with low academic achievement may be at risk for social skills deficits (e.g., hyperactive or aggressive behavior) (Forness \& Kavale, 1996). In our subsample of low-achieving students, 59\% were of non-Swiss nationality, $9 \%$ had an official ADHD diagnosis and 9\% had a diagnosed a conduct disorder. In contrast, 3\% respective $2 \%$ in the sample of adolescents without academic difficulties were diagnosed with ADHD respective conduct disorder and $34 \%$ were of non-Swiss nationality.

Number of cross-group friends (T1). In order to measure cross-group friendships between adolescents with typical academic achievement and their classmates with low academic achievement, adolescents were asked to nominate their best friends from their classroom. To enhance reliability, the number of choices was unlimited (Knoke \& Yang, 2008). Based on these choices, social networks were constructed for each classroom in the statistical environment R (R Development Core Team, 2015). As friendship requires mutuality (Bukowski et al., 2009), we only extracted reciprocated cross-group friendships from the social networks. Following this procedure, $18 \%$ of students with typical academic achievement had at least one cross-group friend $(n=155$, students with friends: range $=1-4$ cross-group friends, $M=1.18, S D=0.45)$. Of these cross-group friendships, the stability of the number of actual cross-group friendships (i.e., with the same classmates) was $75 \%$. Supplemental analyses revealed that the stability of these actual friendships was not significantly related to any demographic variables or key variables of interest of this study. 
Intended inclusion (T1 \& T2). Students were asked to imagine being in another classroom and read a short description about an unfamiliar adolescent with low academic achievement (i.e., "[name of hypothetical child, e.g., Kai] needs a lot of time and support to do class work"). This description was derived from students' knowledge about low-achieving students (e.g., Magiati et al., 2002), and portrayed a typical out-group member with low academic achievement. To control for sex differences, the sex of the protagonist was matched with the sex of the participant. Adolescents rated three questions regarding the social inclusion of this individual on a four-point scale $(1=$ not at all to $4=$ very much $)$. They were asked how willing they would be to invite this student to their birthday party, to spend the break time in school with that student, or to play with that student (for similar scales see Cameron \& Rutland, 2006; Grütter \& Meyer, 2014). Higher scores represented more positive attitudes towards the inclusion of students with low academic achievement.

Intergroup trust (T1 \& T2). We assessed intergroup trust following the items on intended inclusion of students with low academic achievement with three items adapted from prior studies on intergroup trust in adolescents (e.g., Turner et al., 2007). These items focused on emotional aspects of trust (Rotenberg, 2010), such as secret sharing, general trust, and emotional disclosure towards a hypothetical child with low academic achievement (“e.g., Would you trust [Kai] with your most important secret?“). The items were answered on a four-point Likert scale $(1=$ not at all, $4=$ very much). A full description of all the items of each scale can be found in the online appendix S2-B.

Intergroup sympathy (T1 \& T2). This measure consisted of three items adapted from prior studies (Gasser et al., 2013). The items were assessed following the description of the hypothetical student with low academic achievement (see above) and asked adolescents about their emotional reaction if this student was being excluded or treated unfairly (e.g., „Would you feel sorry for [Kai] if he had no friends in school?“). The items were answered 
on a 4-point Likert-scale $(1=$ not at all, $4=$ very much $)$. A full description of all the items of each scale can be found in the online appendix S2-B.

Control variables. We controlled for intergroup anxiety, hyperactivity, emotional problems, and conduct problems at $\mathrm{T} 1$.

We adopted the intergroup anxiety measure from Feddes et al. (2009) and Turner et al. (2007), who modified this scale from the original work of Stephan and Stephan (1985) to be suitable for children. Participants were asked, "Imagine that a new student, who you do not know yet, is introduced to your classroom. He or she needs a lot of time and support to do class work. He or she approaches you during break time and asks you to spend time with him or her. How would you feel?" Answers were assessed on three 5-point semantic differential items: Relaxed-nervous, pleased-worried, and comfortable-tense, and coded so that higher scores reflected higher levels of anxiety towards a typical out-group member with low academic achievement. The sex of the protagonist was matched with the sex of the participant.

Hyperactivity, emotional problems, and conduct problems were measured with scales from the SDQ (Strength and Difficulties Questionnaire; Goodman, 1997). Specifically, for each student, the teachers answered to the five items of the hyperactivity scale (e.g., "Easily distracted, concentration wanders."), of the conduct problems scale (e.g., "Often has temper tantrums or hot tempers."), and of the emotional problems scale ("Many fears, easily scared."). A full description of all the items of each scale can be found in the online appendix S0. The items were answered on a three-point scale $(0=$ not true, $1=$ somewhat true, $2=$ certainly true) and the sum score for each subscale was calculated.

\section{Data Analytic Approach}

To analyze our mediational hypotheses, we specified a parallel latent change score model (see Figure1), which contained the number of cross-group friends at $\mathrm{T} 1$ as a predictor 
of intended inclusion at T2 and the two mediators change in intergroup trust and change in intergroup sympathy. To model the changes of sympathy and trust over time, we used latent change score modeling (Selig \& Preacher, 2009) with three indicators for each latent variable. We chose latent change score modeling for the two mediation hypotheses, because we were interested in the role of intraindividual change in intergroup trust and sympathy and in interindividual differences in this change. Latent change score models capture the development of a construct with two latent random factors: Intercept (e.g., initial levels of trust in hypothetical low-achieving students) and slope (e.g., change over time in intergroup trust; Selig \& Preacher, 2009). As change is represented as a latent construct with a mean and variance component, we were able to simultaneously model intra-individual development (e.g., mean-level changes in intergroup trust and sympathy within adolescents) and interindividual differences in such development (e.g., differences between adolescents in their change in intergroup trust or intergroup sympathy). We hypothesized that the number of cross-group friends would predict higher levels of change in intergroup trust and sympathy and that this change in turn would predict adolescents' intended inclusion. By controlling for individual starting levels (i.e., the intercept) we also partialled out the effects of initial levels of trust and sympathy on their development over time. In other words, we tested if change in trust and sympathy had an additive effect above and beyond the initial levels of trust and sympathy.

To increase the robustness of the model, we controlled for adolescents' intended inclusion at T1. Further, we considered intergroup trust and sympathy simultaneously, examining the unique role of each mediator while also controlling for their interdependence. Thus, we controlled for the correlation between trust and sympathy at $\mathrm{T} 1$ and at the latent level (see Figure 1). In addition, we also included the intercorrelatedness of adolescents' intended inclusion, intergroup trust, and sympathy at both time points; this allowed us to 
examine the effect of adolescents' change in intergroup trust and sympathy on adolescents' inclusive attitudes while holding the relations between these variables within the first and second measurement time constant. As adolescents with high levels of intergroup anxiety may experience cross-group interactions less positive (Stephan \& Stephan, 1985), we controlled for adolescents' initial levels of intergroup anxiety (at T1). Furthermore, preliminary analyses (see Table 1) showed that - compared to girls - boys had lower levels of intergroup trust, intergroup sympathy, and reported lower intended inclusion. Therefore, sex was included as control variable. Since age differences and adolescents' nationality, academic achievement, hyperactivity, emotional, and conduct problems can influence the formation of peer relationships (e.g., Grütter et al., 2015; Rubin, Bukowski, \& Parker, 2006) they may relate to the development of trust and sympathy (Eisenberg et al., 2010; Malti et al., 2016). Thus, we controlled for these variables in our model. Indeed, as visible in the bivariate correlations with these control variables (see online appendix Table S1), some were significant. For example, hyperactivity negatively correlated with intergroup trust at T1 ( $r=-$ $.10, p<.01)$ and intergroup sympathy at T1 and T2 (T1: $r=-.14, p<.01, \mathrm{~T} 2: r=-.09, p<$ .05 ), and conduct problems negatively correlated with intergroup trust at T1 and T2 (T1 \& $\mathrm{T} 2: r=-.11, p<.01)$ and intergroup sympathy at T1 and T2 $(\mathrm{T} 1: r=-.14, p<.01, \mathrm{~T} 2: r=-$ $.11, p<.01)$. All control variables were included in the model as predictors of both mediators (trust and sympathy) and the dependent variable (intended inclusion). Importantly, to strengthen the validity of our hypothesized mediational model, we also tested the plausibility of alternative models: First, we added additional paths predicting the number of cross-group friendships at T2; and second, we reversed the paths of influence. The results of these analyses are reported in the online supplementary file (see S3).

As the students were part of different school classes, we had to consider betweengroup variance (Bliese, 2000). There was no significant between-group variance; thus, we did 
not include the multilevel structure in our final model. The results of the respective analyses are reported in the online appendix S2. Before testing our model, we first assessed measurement invariance (MI) across time. For testing MI, we used confirmatory factor analyses for each measure in a stepwise procedure, with increasing constraints on the factor loadings and intercepts of the items of each scale. As longitudinal MI reveals the consistency with which our constructs of interest were measured over time, this procedure is required to ensure the proper interpretation of the longitudinal findings (Widaman, Ferrer, \& Conger, 2010). A detailed description of the procedure, the respective requirements for each nested model, and the detailed results are reported in the online appendix S2.

All analyses were conducted in Mplus 7.3 and we used full information maximum likelihood (FIML) estimation in order to account for missing data (Muthén \& Muthén, 2014). We evaluated the models based on their comparative fit index (CFI; good fit > .90), their root mean square error of approximation $($ RMSEA; good fit < .07) with the $90 \%$ confidence interval and with their standardized root-mean-square residual (SRMR; good fit < .08; Schermelleh-Engel, Moosbrugger, \& Müller, 2003).

\section{Results}

In line with our main research goal (i.e., how students from the majority group without low academic achievement thought about including students from the minority group with low academic achievement), we removed adolescents from the minority group from the statistical analyses. Nevertheless, students with low academic achievement were included in the description of the sample as their information was used to create the social networks of each classroom and to identify the number of cross-group friends from these social networks. The final sample size used for the analyses contained $n=877$ students at T1 and $n=747$ students at T2 who showed a typical development of their academic skills.

\section{General Model}


The hypothesized model fit the data well, $\chi^{2}(234)=457.69, p<.001, \mathrm{CFI}=.97$, RMSEA $=.04$ [90\% CI: $.03-.04, p=1.00]$, SRMR $=.03$. The results from the model showed that at $\mathrm{T} 1$, the number of cross-group friendships did not predict intergroup sympathy (intercept) nor intended inclusion (see Figure 1). In addition, the number of cross-group friends negatively related to intergroup trust (intercept) at T1 (see Figure 1). The effects of the control variables are reported in Table 1. In particular, intergroup sympathy, intergroup trust, and intended inclusion at T1 were significantly related to the level of intergroup anxiety at T1 (see Table 1). Thus, individuals with higher levels of intergroup anxiety showed significantly lower intergroup trust, lower intergroup sympathy and lower intended inclusion at T1. Furthermore, the results revealed that hyperactivity was significantly related to higher increases in intergroup trust.

Additionally, there was significant variance in the latent change score of intergroup trust $\left(\zeta^{2}=0.58, S E=.04, p<.001\right)$ and sympathy $\left(\zeta^{2}=.66, S E=0.03, p<.001\right)$; this means that there were significant differences between individuals in their intraindividual change in intergroup trust and sympathy.

\section{Mediation Analysis}

Intergroup trust. In line with our hypothesis, the number of cross-group friends at T1 significantly predicted an increase (i.e., the slope) in intergroup trust (path al) which in turn predicted intended inclusion at T2 (path $b 1$; see Figure 1). To test for the significance of this indirect effect (alb1), we estimated the 95\% confidence intervals (CI) using the biascorrected bootstrap method (MacKinnon, Lockwood, \& Williams, 2004). This procedure has been found to be highly powerful in testing the statistical significance of mediated effects (MacKinnon et al., 2004). The results of 5000 bootstrapped samples showed that the unstandardized mediated effect was statistically significant $(a 1 b 1=.05, S E=0.02,95 \% \mathrm{CI}$ $[.011, .101])$, as the $95 \%$ lower and upper CI limits did not include zero. Thus, the increasing 
mean-level in intergroup trust from $\mathrm{T} 1$ to $\mathrm{T} 2$ mediated the positive effect of the number of cross-group friends at $\mathrm{T} 1$ on intended inclusion at $\mathrm{T} 2$.

Intergroup sympathy. Hypothesis two assumed that - according to the hypothesis for intergroup trust - students with cross-group friends would increase in their intergroup sympathy over the year and that this change would result in higher intended inclusion. In line with this assumption, the number of cross-group friends at T1 was significantly and positively related to the latent change in intergroup sympathy (path $a 2$ ), and this increase in intergroup sympathy was significantly associated with intended inclusion (path $b 2$; see Figure 1). In other words, the more cross-group friends adolescents had, the more they increased in their intergroup sympathy over time; this increased intergroup sympathy in turn predicted intended inclusion. Using the same bias-corrected bootstrapping method employed for intergroup trust, the results indicated that the unstandardized mediated effect of intergroup sympathy was statistically significant $(a 2 b 2=.03, S E=0.02,95 \%$ CI $[.005, .069])$.

\section{Discussion}

This study investigated friendships between adolescents with low academic achievement and their peers with typical academic achievement in inclusive classrooms. As the primary goal of inclusive education is to enhance the social participation of students with higher learning needs, this study investigated if such friendships lead to more inclusive attitudes among the majority group of students without low academic achievement. The second goal of this study was to gain an understanding of the processes that mediate this relation, as this knowledge can provide insights into how inclusive intergroup attitudes emerge. We specifically focused on the role of change in intergroup trust and sympathy and investigated if such friendships would lead to changes in intergroup trust and sympathy, and whether these changes would predict attitudes towards the inclusion of students with low academic achievement in the long run. 


\section{The Role of Cross-Group Friendship for Adolescents' Inclusive Intergroup Attitudes}

The findings from a parallel latent change score model indicated that trust and sympathy for hypothetical out-group members with low academic achievement increased over the school year in individuals with typical academic achievement if they had a higher number of cross-group friends. This increase in turn predicted inclusion towards hypothetical students with low academic achievement one year later. This finding speaks to the significance of cross-group friendships in inclusive school classes and is in line with prior results showing a positive relation between cross-group friendships and positive attitudes towards students with higher learning needs (Grütter \& Meyer, 2014). Additionally, prior research also suggests that contact between children with different abilities results in higher acceptance of inclusive schooling (Kalyva \& Agaliotis, 2009). Extending this prior research that was based on correlational findings, this is the first study that employed a longitudinal design to analyze the relation between cross-group friendships and adolescents' inclusive attitudes towards students with low academic achievement.

Moreover, focusing on a sample of early adolescents in the context of inclusive schools, this study also demonstrates that cross-group friendships may still be of particular significance, even though early adolescents face higher academic pressure. In Switzerland, early adolescents transfer to secondary school at grade seven. The different types of secondary schools require different levels of academic achievement, which is why adolescents' academic achievement is under scrutiny during grades five and six. This means that the adolescents in our sample may have been under a strong pressure to perform and therefore, less willing to include students with low academic achievement. Previous studies show that although the majority of adolescents perceive the exclusion of a student with intellectual disabilities as wrong, they may still decide to exclude hypothetical classmates with mental impairments in contexts in which they perceive negative consequences for their 
in-group (e.g., solving a difficult math task; Gasser et al., 2013, 2014). With regard to the findings of our study, adolescents may have been more likely to exclude a hypothetical student with low academic achievement, as the inclusion of this student might have impeded effective academic group functioning. Findings from a recent study suggest that the context of increased academic pressure may even increase adolescents' decisions to exclude individuals with low academic achievement, as their low academic performance does not conform to group norms of well performing groups (Gasser, Grütter, Torchetti, \& Buholzer, 2017).

Still, the findings of this research suggest that cross-group friendships can have a positive effect on adolescents' inclusive attitudes. This positive impact can be explained with the heightened significance of friendships in general, whereby friends play an important role in the socialization of adolescents' behaviors and opinions (Newcomb \& Bagwell, 1995; Shin \& Ryan, 2014). If adolescents perceive that it is acceptable to be friends with low-achieving students, these low-achieving students have a better chance at being accepted by peers. Accordingly, previous research shows that cross-group friendships can change the perceived social norm that it is acceptable to be friends with out-group members, which in turn predicts more favorable intergroup attitudes (Feddes et al., 2009).

In addition to group norms, the positive effects of cross-group friendships can be explained by the increased significance of affective characteristics of friendships during this period (Bukowski et al., 2009; Newcomb \& Bagwell, 1995). As the current study investigated two underlying processes through which adolescents with cross-group friendships develop positive intergroup attitudes (i.e., intergroup trust and sympathy), this study provides a better understanding of how prejudice can be reduced during this sensitive period of increased academic pressure that may pose conflicting demands for adolescents: 
Belonging to high achieving peer groups or being inclusive towards students with low academic achievement (Gasser et al., 2017).

\section{The Role of Intergroup Trust and Sympathy in Cross-Group Friendship}

Extending prior research (e.g., Turner et al., 2007), this study shows that cross-group friendships with low-achieving students may go along with increasing trust in hypothetical students with low academic achievement, and that this increase in turn predicts more inclusive attitudes longitudinally. As a conclusion, cross-group friendships that are characterized by higher levels of intergroup trust may be significant in reducing prejudice during adolescence. In addition to trust, the results of this study suggest that intergroup sympathy may reflect another central component for promoting inclusive attitudes among adolescents. This finding is in line with a previous study that revealed a significant correlation between children's contact intensity with classmates who had a mental disability and their sympathy towards a hypothetical classmate with a mental disability (Gasser et al., 2013). However, this study only had a cross-sectional design; thus it remained unclear whether students with higher levels of contact developed more intergroup sympathy or whether students with higher levels of sympathy were more likely to interact with disabled classmates. Extending these first results, the findings of the present study showed that crossgroup friendships led to the development of higher levels of intergroup sympathy over a year and that this increased intergroup sympathy in turn predicted more inclusive intergroup attitudes. To corroborate our findings, we also tested alternative models, in which the number of cross-group friendships at the second measurement time was predicted by intergroup trust and sympathy at T1 (see online appendix S3). Neither intergroup trust nor intergroup sympathy significantly predicted the number of cross-group friends one year later, further supporting our hypotheses. Taken together, sympathy towards hypothetical low-achieving out-group members may emerge from friendships between typically achieving and low- 
achieving adolescents, predicting the development of inclusive intergroup attitudes. Thus, in order to develop more inclusive intergroup attitudes, individuals need to sympathize with outgroup members. As sympathy reflects feelings of concern that result from the apprehension of others' emotional states (Eisenberg et al., 2010), adolescents' feelings of concern for lowachieving students may be of particular importance in the context of inclusive education.

\section{The Role of Individual Differences in Cross-Group Friendship}

Importantly, by using a parallel latent change score model, we accounted for the processes underlying cross-group friendship and assumed a dynamic understanding of how intergroup trust and sympathy may increase over time. We also controlled for adolescents' initial levels of trust and sympathy; while holding these initial levels of trust and sympathy constant, the results showed a significant variability between individuals in their change over time. In other words, some adolescents changed more than others in a systematic way, with some adolescents increasing more than others. This finding resonates with recent related research on individual differences in intergroup contact in adult samples. Specifically, researchers have argued that there is little sense in theorizing a general recipe of intergroup contact as a mean to reduce prejudice without acknowledging individual differences (Hodson, Costello, \& MacInnis, 2013).

Prior studies regarding cross-group friendship using children or adolescent samples do not explain why intergroup contact may be more beneficial for some individuals than for others. Allport (1954) acknowledged that contact rarely succeeds among all individuals uniformly; nevertheless, individual differences have remained unexamined till recently (Hodson et al., 2013), and there has been little prior research regarding children or adolescents (for exceptions see for example Munniksma, Stark, Verkuyten, Flache, \& Veenstra, 2013). In this study, we also accounted for the possibility that students' development of intergroup trust and sympathy may depend on individual differences in 
students' social development. The findings of this study suggest that particularly individuals with high levels of hyperactivity may develop higher intergroup trust over time. In other words, cross group friendships may particularly benefit hyperactive students who do have difficulties in their social skills like self-reflection and social perception (Hoza, 2007). However, this increase in intergroup trust may also have its origins in the kinds of social interactions individuals are having (Rubin et al., 2006), and thus, depend on the social characteristics of out-group friends. Future studies employing a social network design may thus focus on the development of intergroup trust and sympathy with regard to selection and influence processes in the formation of friendships. Such studies may also explain why girls changed more in their levels of intergroup trust and sympathy over time than boys, as boys are more likely for showing hyperactive or socially disruptive behavior and may prefer to befriend other boys with similar characteristics (Goodman, 1997; Rubin et al., 2006). In addition, the quality of friendships may differ as a function of adolescents' gender, nationality, and social skills (Newcomb \& Bagwell, 1995; Padilla-Walker et al., 2015; Rubin et al., 2006). Thus, future research may specifically address the role of friendship quality in cross-group friendships for the development of inclusive intergroup attitudes.

\section{Intergroup Anxiety and the Development of Adolescents' Inclusive Intergroup Attitudes}

In this study, the number of cross-group friendships at the first measurement time (T1) was not significantly related to intergroup sympathy but was negatively related to intergroup trust. A possible explanation for these missing or negative effects may be that students with typical achievement levels displayed higher levels of intergroup anxiety at T1. Accordingly, higher levels of intergroup anxiety significantly predicted lower intergroup sympathy, lower intergroup trust, and less inclusive attitudes at T1.

Intergroup anxiety is an important mediator of intergroup contact (Pettigrew \& Tropp, 2008), particularly when there has been little previous social interaction (Turner et al., 2007). 
During such novel intergroup interactions, individuals with high levels of intergroup anxiety may expect rejection or discrimination. As a consequence, they may focus on the negative aspects of the individual and may rely on stereotypes when evaluating out-group members. Therefore, high levels of intergroup anxiety can impede positive effects of intergroup contact and as a result, may even worsen intergroup attitudes (Stephan \& Stephan, 1985).

Regarding our sample, most of the cross-group friendships may have been formed more recently, as classrooms are newly composed in most regions of Switzerland when student transfer from grade four to grade five (T1). Thus, even students with cross-group friends may still have had higher levels of intergroup anxiety: They may have felt uncomfortable about being alone with an unfamiliar low-achieving student and consequently reported significantly lower trust in and lower sympathy for hypothetical low-achieving students. Furthermore, if individuals expect negative experiences from intergroup interactions, individuals may express lower levels of intergroup trust. Over time however, individuals with cross-group friends may develop higher trust in hypothetical out-group members, leading to more inclusive intergroup attitudes. Accordingly, prior studies showed that a decrease in intergroup anxiety was related to an increase in intergroup trust (Swart, Hewstone, Turner, \& Voci, 2011). The results of the current study align with these previous findings and show that although intergroup anxiety was negatively correlated with intergroup trust at $\mathrm{T} 1$, it did not predict changes in intergroup trust over time.

Taken together, based on previous research (Swart, Hewstone, Christ et al., 2011; Swart, Hewstone, Turner et al., 2011; Turner et al., 2007), the results of this study suggest that intergroup anxiety may hinder the positive consequences of cross-group friendships in early stages of friendship. Over time, however, anxiety may dissolve, as children with these friendships increase in their intergroup trust and sympathy. Consequently, developing new cross-group friendships may be important for reducing negative intergroup attitudes as such 
friendships may be most beneficial for fostering intergroup trust and sympathy in individuals who are more biased (i.e., with higher levels of intergroup anxiety). As intergroup anxiety is an important component in the development of inclusive intergroup attitudes, future studies could shed more light on the antecedents of adolescents' experiences of such negative emotions within inclusive school environments.

\section{Practical Implications}

The findings of this study suggest that promoting cross-group friendships may foster inclusive and accepting school environments. To promote such friendships, schools may provide opportunities for collaboration and out-of-class voluntary contact between students, because proximity is an important prerequisite for the formation of friendships (Tropp \& Prenovost, 2008). However, promoting cross-group friendships may pose a challenge for professionals within inclusive education since friendship is seen as a personal choice and children regard exclusion of peers from friendship contexts as acceptable (Killen, Lee-Kim, McGlothlin, \& Stangor, 2002). Therefore, alternative ways of promoting inclusive intergroup attitudes are warranted. By understanding the key processes that lead to positive effects of cross-group friendships, this study can provide important information on how such alternative ways might look like. For example, previous studies have shown that students who listened to stories about a friendship between hypothetical children with and without disabilities led to more positive attitudes and higher intentions to interact with disabled children in general (Cameron \& Rutland, 2006; Cameron, Rutland, \& Brown, 2007). Thus, with regard to our study findings, such stories could promote inclusive intergroup attitudes, particularly, if these stories revolve around intergroup trust and sympathy.

Furthermore, since the results of this study suggest that encouraging trust and sympathy for students with low academic achievement may bud inclusive attitudes in adolescents with typical academic achievement, the development of trust in, and concern for, 
students with different academic abilities may be significant for inclusive school environments. Therefore, teachers may specifically target classroom environments that promote the development of trust and sympathy. Moreover, since teachers act as a role model for students, their behavior towards a certain student can predict that child's peer acceptance (Mikami, Lerner, \& Lun, 2010). Therefore, teachers may carefully consider how their daily social interactions with students with low-academic achievement may influence these children's social inclusion.

\section{Limitations}

This study is not without limitations. First, although allowing for more reliable assumptions regarding the positive consequences of cross-group friendships and the mediation hypotheses, the study contained only two waves of data collection. In order to employ a full mediation model, three waves would be required (Selig \& Preacher, 2009).

Second, prior studies emphasize a bidirectional and dynamic understanding of the intergroup contact - prejudice relation (e.g., Munniksma et al., 2015) whereby the link from friendship to attitudes has been shown to be stronger (Swart, Hewstone, Christ et al., 2011). In this study, we did not control for adolescents' number of cross-group friends at T2 in our final model, as our primary interest concerned adolescents' inclusive attitudes. Still, in order to corroborate our findings, we also tested alternative paths. The results of these additional analyses (see online appendix S3) revealed that our hypothesized model fit the data better than a model in which the number of cross-group friendships at T2 was predicted by intergroup trust, sympathy, and inclusive attitudes at $\mathrm{T} 1$ and a model with reversed causality. Moreover, cross-group friendships were highly stable across the two time points; nevertheless, we did not have any information about the duration of friendships. Therefore, we did not know how long adolescents had been friends for.

Third, although we were able to assess intergroup trust and sympathy at two time 
points, we were not able to suggest timely relations between the variables. In this study, we tested intergroup sympathy and trust simultaneously while controlling for their correlation, as we assumed a bidirectional relation between intergroup trust and sympathy. In contrast, some studies assume, for example, that cross-group friendship leads to enhanced empathy, and this in turn would enhance out-group trust ( Swart, Hewstone, Turner et al., 2011; Turner et al., 2007). However, these studies have been cross-sectional and it remains unclear, whether trust would need to be established first in order to enhance empathy. In order to examine such timely relations, future research using a multi-waves design may shed light on this question regarding the importance of intergroup sympathy and trust in the process of friendship formation.

Fourth, regarding our sample, there were proportionally more students of non-Swiss nationality (59\%) in the low-achieving group than in the typically achieving group (34\%). Thus, there was some overlap between low-academic achievement and nationality. While nationality was included in our model as a control variable, it may stille be possible that typically achieving students who had low-achieving friends also had non-Swiss friends at the same time. In other words, while we were able to control for students' own nationality in the model, it was not possible to control for their cross-group friends' nationality. In order to fully disentangle possible effects of cross-group friendships with low-achieving students and cross-group friendships with non-Swiss students, future research should focus on this intersectionality of mutliple out-groups and identify if the same processes are at work for both social categories.

Fifth, friendships are not only important for the majority group, but also for the minority group of students with low academic achievement, as it is an important predictor for individual wellbeing, for self-worth, and for adjustment to school (Bagwell, Newcomb, \& Bukowski, 1998). Furthermore, the literature on intergroup contact suggests that the benefits 
are more apparent for majority group members than for minority group members (Pettigrew $\&$ Tropp, 2006). Thus, studying the role of intergroup trust and sympathy for cross-group friendships in the social development of students with low academic achievement would have provided important insights into the effects and processes for the minority group of lowachieving students. In short, studying benefits of cross-group friendships for low-achieving students remains an important area for future research.

Lastly, the development of adolescents' intergroup attitudes may also depend on the social context; thus, how teachers design the school environment may shape students' social experiences (Mikami et al., 2010) and moderate the relation between cross-group friendships and inclusive intergroup attitudes (e.g., Grütter \& Meyer, 2014). For example, if students with low-academic achievement are educated separately from the other students for most of the day (even though these students visit inclusive classrooms) they may be less accepted by their classmates (Wiener \& Tardif, 2004). Thus, future research that examines how such contextual information relate to students' development of intergroup trust and sympathy could provide more insights into how inclusive school environments would need to be designed in order to promote socially responsible behavior among adolescents.

\section{Conclusion}

In sum, this study shows that friendships between students with low academic achievement and their typically developing peers may enhance inclusive attitudes of the majority group of adolescents with average or high academic achievement. This positive effect is explained by increasing trust in, and sympathy for hypothetical out-group members in adolescents with cross-group friendships; therefore, such friendships relate to higher peer inclusivity. Consequently, intergroup trust and sympathy may be key components in promoting acceptance in inclusive classrooms. 


\section{References}

Abbott, N., \& Cameron, L. (2014). What makes a young assertive bystander? The effect of intergroup contact, empathy, cultural openness, and in-group bias on assertive bystander intervention intentions. Journal of Social Issues, 70, 167-182. doi:10.1111/josi.12053

Aboud, F. E., \& Spears Brown, C. (2013). Positive and negative intergroup contact among children and its effect on attitudes. In G. Hodson \& M. Hewstone (Eds.), Advances in intergroup contact (pp. 176-199). New York: Routledge. doi:10.4324/9780203095461

Allport, G. W. (1954). The nature of prejudice. Reading, MA: Addison-Wesley Publishing Company.

Armstrong, M., Morris, C., Abraham, C., Ukoumunne, O. C., \& Tarrant, M. (2016). Children's contact with people with disabilities and their attitudes towards disability: A crosssectional study. Disability and Rehabilitation, 38, 879-888.

doi:10.3109/09638288.2015.1074727

Bagwell, C. L., Newcomb, A. F., \& Bukowski, W. M. (1998). Preadolescent friendship and peer rejection as predictors of adult adjustment. Child Development, 69, 140-153. doi:10.1111/j.1467-8624.1998.tb06139.x

Bakker, J. T. A., \& Bosman, A. M. T. (2003). Self-image and peer acceptance of Dutch students in regular and special education. Learning Disability Quarterly, 26, 5-14. doi: $10.2307 / 1593680$

Bates, H., McCafferty, A., Quayle, E., \& McKenzie, K. (2015). Review: Typically-developing students' views and experiences of inclusive education. Disability and Rehabilitation, 37, 1929-1939. doi: 10.3109/09638288.2014.993433

Bliese, P. D. (2000). Within-group agreement, non-independence, and reliability: Implications for data aggregation and analysis. In K. J. Klein \& S. W. Kozlowski (Eds.), Multilevel theory, research, and methods in organizations (pp. 349-381). San Francisco: Jossey- 
Bass.

Bukowski, W. M. (2001). Friendship and the worlds of childhood. In D. W. Nangle \& C. A. Erdley (Eds.), The role of friendship in psychological adjustment: Vol. 91. New directions for child and adolescent development (pp. 93-106). San Francisco: Jossey-Bass.

Bukowski, W., Motzoi, C., \& Meyer, F. (2009). Friendship as process, function, and outcome. In K. H. Rubin, W. M. Bukowski, \& B. Laursen (Eds.), Handbook of peer interactions, relationships, and groups (pp. 217-231). New York: Guilford Press.

Cameron, L., \& Rutland, A. (2006). Extended contact through story reading in school: Reducing children's prejudice toward the disabled. Journal of Social Issues, 62, 469-488. do: $10.1111 / \mathrm{j} .1540-4560.2006 .00469 . x$

Cameron, L., Rutland, A., \& Brown, R. J. (2007). Promoting children's positive intergroup attitudes towards stigmatized groups: Extended contact and multiple classification skills training. International Journal of Behavioral Development, 31, 454-466. doi: $10.1177 / 0165025407081474$

Eisenberg, N., Eggum, N. D., \& Di Giunta, L. (2010). Empathy-related responding: Associations with prosocial behavior, aggression, and intergroup relations. Social Issues and Policy Review, 4, 143-180. doi: 10.1111/j.1751-2409.2010.01020.x

Feddes, A. R., Noack, P., \& Rutland, A. (2009). Direct and extended friendship effects on minority and majority children's interethnic attitudes: A longitudinal study. Child Development, 80, 377-390. doi: 10.1111/j.1467-8624.2009.01266.x

Flashman, J. (2012). Academic achievement and its impact on friend dynamics. Sociology of Education, 85, 61-80. doi: 10.1177/0038040711417014

Forness, S. R., \& Kavale, K. A. (1996). Treating social skill deficits in children with learning disabilities: A meta-analysis of the research. Learning Disability Quarterly, 19, 2-13. doi: $10.2307 / 1511048$ 
Gasser, L., Grütter, J., Torchetti, L., \& Buholzer, A. (2017). Competitive classroom norms and exclusion of children with academic and behavior difficulties. Journal of Applied Developmental Psychology, 49, 1-11. doi: 10.1016/j.appdev.2016.12.002

Gasser, L., Malti, T., \& Buholzer, A. (2013). Children's moral judgments and moral emotions following exclusion of children with disabilities: Relations with inclusive education, age, and contact intensity. Research in Developmental Disabilities, 34, 948-958. doi: 10.1016/j.ridd.2012.11.017

Gasser, L., Malti, T., \& Buholzer, A. (2014). Swiss children's moral and psychological judgments about inclusion and exclusion of children with disabilities. Child Development, 85, 532-548. doi: 10.1111/cdev.12124

Goodman, R. (1997). The strengths and difficulties questionnaire: A research note. Journal of Child Psychology and Psychiatry, 38, 581-586. doi:10.1111/j.1469-7610.1997.tb01545.x

Grütter, J., \& Meyer, B. (2014). Intergroup friendship and children's intentions for social exclusion in integrative classrooms: The moderating role of teachers' diversity beliefs. Journal of Applied Social Psychology, 44, 481-494. doi: 10.1111/jasp.12240

Grütter, J., Meyer, B., \& Glenz, A. (2015). Sozialer Ausschluss in Integrationsklassen: Ansichtssache? [Social exclusion in inclusive classrooms: A question of viewpoint?] Psychologie in Erziehung und Unterricht, 62, 65-82. doi:10.2378/peu2015.art05d

Hodson, G., Costello, K., \& MacInnis, C. C. (2013). Is intergroup contact beneficial among intolerant people? Exploring individual differences in the benefits of contact on attitudes. In Advances in intergroup contact. (pp. 49-80). London, UK: Psychology Press.

Hoza, B. (2007). Peer functioning in children with ADHD why are peer relationships important. Journal of Pediatric Psychology, 32, 655-663. doi: 10.1093/jpepsy/jsm024

Hughes, J. N., Dyer, N., Luo, W., \& Kwok, O. (2009). Effects of peer academic reputation on achievement in academically at-risk elementary students. Journal of Applied 
Developmental Psychology, 30, 182-194. doi: 10.1016/j.appdev.2008.12.008

Kahn, P. H., \& Turiel, E. (1988). Children's conceptions of trust in the context of social expectations. Merrill-Palmer Quarterly, 34, 403-419.

Kalyva, E., \& Agaliotis, I. (2009). Can contact affect Greek children's understanding of and attitudes towards peers with physical disabilities? European Journal of Special Needs Education, 24, 213-220. doi:10.1080/08856250902793701

Killen, M., Lee-Kim, J., McGlothlin, H., \& Stangor, C. (2002). How children and adolescents evaluate gender and racial exclusion. Monographs of the Society for Research in Child Development, 67(4). doi: 10.1111/1540-5834.00220

Knoke, D., \& Yang, S. (2008). Social network analysis. Los Angeles: Sage Publications.

MacKinnon, D. P., Lockwood, C. M., \& Williams, J. (2004). Confidence limits for the indirect effect: Distribution of the product and resampling methods. Multivariate Behavioral Research, 39, 99-128. doi:10.1207/s15327906mbr3901_4

Magiati, I., Dockrell, J. E., \& Logotheti, A. (2002). Young children's understanding of disabilities: The influence of development, context, and cognition. Journal of Applied Developmental Psychology, 23, 409-430. doi: 10.1016/S0193-3973(02)00126-0

Malti, T., Averdijk, M., Zuffiano, A., Ribeaud, D., Betts, L. R., Rotenberg, K. J., \& Eisner, M. P. (2016). Children's trust and the development of prosocial behavior. International Journal of Behavioral Development, 40, 262-270. doi: 10.1177/0165025415584628

Maxwell, S. E., Cole, D. A., \& Mitchell, M. A. (2011). Bias in cross-sectional analyses of longitudinal mediation: Partial and complete mediation under an autoregressive model. Multivariate Behavioral Research, 46, 816-841. doi:10.1080/00273171.2011.606716

Mikami, A. Y., Lerner, M. D., \& Lun, J. (2010). Social context influences on children's rejection by their peers. Child Development Perspectives, 4, 123-130. doi: 10.1111/ j.1750-8606.2010.00130.x 
Munniksma, A., Stark, T. H., Verkuyten, M., Flache, A., \& Veenstra, R. (2013). Extended intergroup friendships within social settings: The moderating role of initial outgroup attitudes. Group Processes \& Intergroup Relations, 16, 752-770. doi: $10.1177 / 1368430213486207$

Munniksma, A., Verkuyten, M., Flache, A., Stark, T. H., \& Veenstra, R. (2015). Friendships and outgroup attitudes among ethnic minority youth: The mediating role of ethnic and host society identification. International Journal of Intercultural Relations, 44, 88-99. doi: 10.1016/j.ijintrel.2014.12.002

Muthén, L. K., \& Muthén, B. O. (2014). Mplus User's Guide (7th ed.). Los Angeles, CA: Muthén \& Muthén.

Nabuzoka, D. (2003). Teacher ratings and peer nominations of bullying and other behavior of children with and without learning difficulties. Educational Psychology, 23, 307-321. doi: $10.1080 / 0144341032000060147$

Newcomb, A. F., \& Bagwell, C. L. (1995). Children's friendship relations: A meta-analytic review. Psychological Bulletin, 117, 306-347. doi: 10.2307/353560

Nowicki, E. A. (2012). Intergroup evaluations and norms about learning ability. Social Development, 21, 130-149. doi: 10.1111/j.1467-9507.2011.00614.x

Nowicki, E. A., \& Sandieson, R. (2002). A meta-analysis of school-age children's attitudes towards persons with physical or intellectual disabilities. International Journal of Disability, Development and Education, 49, 243-265. doi:

$10.1080 / 1034912022000007270$

Padilla-Walker, L. M., Fraser, A. M., Black, B. B., \& Bean, R. A. (2015). Associations between friendship, sympathy, and prosocial behavior toward friends. Journal of Research on Adolescence, 25, 28-35. doi:10.1111/jora.12108

Pettigrew, T. F., \& Tropp, L. R. (2006). A meta-analytic test of intergroup contact theory. 
Journal of Personality and Social Psychology, 90, 751-783. doi: 10.1037/00223514.90.5.751

Pettigrew, T. F., \& Tropp, L. R. (2008). How does intergroup contact reduce prejudice? Metaanalytic tests of three mediators. European Journal of Social Psychology, 38, 922-934. doi: $10.1002 /$ ejsp.504

R Development Core Team (2015). $R$ : A language and environment for statistical computing. Computer Software. Vienna, Austria: R Foundation for Statistical Computing. Retrieved from http://www.R-project.org

Rotenberg, K. J. (1986). Same-sex patterns and sex differences in the trust-value basis of children's friendship. Sex Roles, 15, 613-626. doi:10.1007/BF00288218

Rotenberg, K. J. (2010). The conceptualization of interpersonal trust: A basis, domain, and target framework. In K. J. Rotenberg (Ed.), Interpersonal trust during childhood and adolescence (pp. 8-27). doi: 10.1017/CBO9780511750946.002

Rotenberg, K. J., \& Cerda, C. (1994). Racially based trust expectancies of native American and Caucasian children. Journal of Social Psychology, 134, 621-631. doi:10.1080/00224545.1994.9922992

Rubin, K. H., Bukowski, W. M., \& Parker, J. G. (2006). Peer interactions, relationships, and groups. In N. Eisenberg, W. Damon \& R. M. Lerner (Eds.), Handbook of child psychology: Vol. 3. Social, emotional, and personality development, 6th ed. (pp. 571645). New York, NY: Wiley \& Sons Inc.

Sabornie, E. J. (1994). Social-affective characteristics in early adolescents identified as learning disabled and nondisabled. Learning Disability Quarterly, 17, 268-279. doi: $10.2307 / 1511124$

Schermelleh-Engel, K., Moosbrugger, H., \& Müller, H. (2003). Evaluating the fit of structural equation models: Test of significance and descriptive goodness-of-fit measures. Methods 
of Psychological Research Online, 8, 23-74. Retrieved from http://www.dgps.de/fachgruppen/methoden/mpr-online/issue20/art3/mpr130_13.pdf

Selig, J. P., \& Preacher, K. J. (2009). Mediation models for longitudinal data in developmental research. Research in Human Development, 6, 144-164. doi: $10.1080 / 15427600902911247$

Shin, H., \& Ryan, A. M. (2014). Early adolescent friendships and academic adjustment: Examining selection and influence processes with longitudinal social network analysis. Developmental Psychology, 50, 2462-2472. doi: 10.1037/a0037922

Smith, E. R. \& Mackie, D. M. (2015). Dynamics of group-based emotions: Insigths from intergroup emotions theory. Emotion Review, 7, 349-354. doi:

$10.1177 / 1754073915590614$

Stephan, W. G., \& Stephan, C. W. (1985). Intergroup anxiety. Journal of Social Issues, 41, 157-175. doi:10.1111/j.1540-4560.1985.tb01134.x

Swart, H., Hewstone, M., Christ, O., \& Voci, A. (2011). Affective mediators of intergroup contact: A three-wave longitudinal study in South Africa. Journal of Personality and Social Psychology, 101, 1221-1238. doi: 10.1037/a0024450

Swart, H., Hewstone, M., Turner, R. N., \& Voci, A. (2011). Achieving forgiveness and trust in postconflict societies: The importance of self-disclosure and empathy. In L. R. Tropp \& R. Mallett (Eds.), Beyond prejudice reduction: Pathways to positive intergroup relations (pp. 181-200). Washington, D.C.: American Psychological Association.

Tam, T., Hewstone, M., Kenworthy, J., \& Cairns, E. (2009). Intergroup trust in Northern Ireland. Personality and Social Psychology Bulletin, 35, 45-59. doi: $10.1177 / 0146167208325004$

Tropp, L. R., \& Prenovost, M. A. (2008). The role of intergroup contact in predicting children's interethnic attitudes: Evidence from meta-analytic and field studies. In S. R. 
Levy \& M. Killen (Eds.), Intergroup attitudes and relations in childhood through adulthood (pp. 236-248). New York, NY: Oxford University Press.

Turner, R. N., Hewstone, M., Swart, H., Tam, T., Myers, E., \& Tausch, N. (2010). Promoting intergroup trust among adolescents and young adults. In K. J. Rotenberg (Ed.), Interpersonal trust during childhood and adolescence (pp. 295-321). doi: 10.1017/CBO9780511750946.014

Turner, R. N., Hewstone, M., \& Voci, A. (2007). Reducing explicit and implicit outgroup prejudice via direct and extended contact: The mediating role of self-disclosure and intergroup anxiety. Journal of Personality and Social Psychology, 93, 369-388. doi: 10.1037/0022-3514.93.3.369

United Nations (2006). Convention on the rights of persons with disabilities. Retrieved from http://www.un.org/disabilities/

United Nations Educational, Scientific and Cultural Organization (1994). The Salamanca statement and framework for action on special needs education. New York: UNESCO. Retrieved from http://www.unesco.org/education/pdf/SALAMA_E.PDF

Vaughn, S., Elbaum, B. E., \& Schumm, J. S. (1996). The effects of inclusion on the social functioning of students with learning disabilities. Journal of Learning Disabilities, 29, 599-608. doi: 10.1177/002221949602900604

Widaman, K. F., Ferrer, E., \& Conger, R. D. (2010). Factorial invariance within longitudinal structural equation models: Measuring the same construct across time. Child Development Perspectives, 4, 10-18. doi:10.1111/j.1750-8606.2009.00110.x

Wiener, J. \& Tardif, C. Y. (2004). Social and emotional functioning of children with learning disabilities: Does special education placement make a difference? Learning Disabilities Research and Practice, 19, 20-32. doi: 10.1111/j.1540-5826.2004.00086.x 


\section{Tables}

Table 1

Parameter Estimates for the Control Variables Sex, Age, Nationality, Academic Achievement, Hyperactivity, Emotional Problems, Conduct

Problems, and Intergroup Anxiety

\begin{tabular}{|c|c|c|c|c|c|c|}
\hline & $\begin{array}{c}\text { Intergroup trust } \\
T 1\end{array}$ & $\begin{array}{c}\text { Intergroup } \\
\text { sympathy } T 1\end{array}$ & $\begin{array}{c}\text { Intended inclusion } \\
T 1\end{array}$ & $\begin{array}{c}\text { Latent difference } \\
\text { trust }\end{array}$ & $\begin{array}{c}\text { Latent difference } \\
\text { sympathy }\end{array}$ & $\begin{array}{c}\text { Intended inclusion } \\
T 2\end{array}$ \\
\hline & $B$ & $B$ & $B$ & $B$ & $B$ & $B$ \\
\hline Sex & $-0.29 * * *$ & $-0.18 * * *$ & $-0.11 *$ & $-0.23 * * *$ & $-0.21 * * *$ & 0.02 \\
\hline Age & 0.03 & -0.01 & 0.03 & -0.01 & -0.02 & -0.03 \\
\hline Nationality & 0.02 & 0.01 & -0.03 & $0.11 *$ & 0.03 & -0.03 \\
\hline Academic Achievement & 0.03 & 0.02 & -0.05 & 0.03 & 0.04 & -0.04 \\
\hline Hyperactivity & 0.01 & -0.01 & 0.01 & $0.03 * *$ & 0.02 & 0.01 \\
\hline Emotional Problems & -0.01 & -0.01 & 0.02 & 0.02 & 0.02 & -0.01 \\
\hline Conduct Problems & -0.03 & $-0.04 *$ & -0.02 & -0.03 & -0.02 & -0.03 \\
\hline Intergroup Anxiety & $-0.18 * * *$ & $-0.18 * * *$ & $-0.10 * * *$ & -0.04 & -0.04 & -0.02 \\
\hline
\end{tabular}

Note. $\mathrm{T} 1$ = first measurement time; $\mathrm{T} 2$ = second measurement time; sex = 0 (female), 1 (male); nationality = 0 (non-Swiss), 1 (Swiss).

$* p<.05, * *=p<.01, * * *=\mathrm{p}<.001$, two-tailed. 


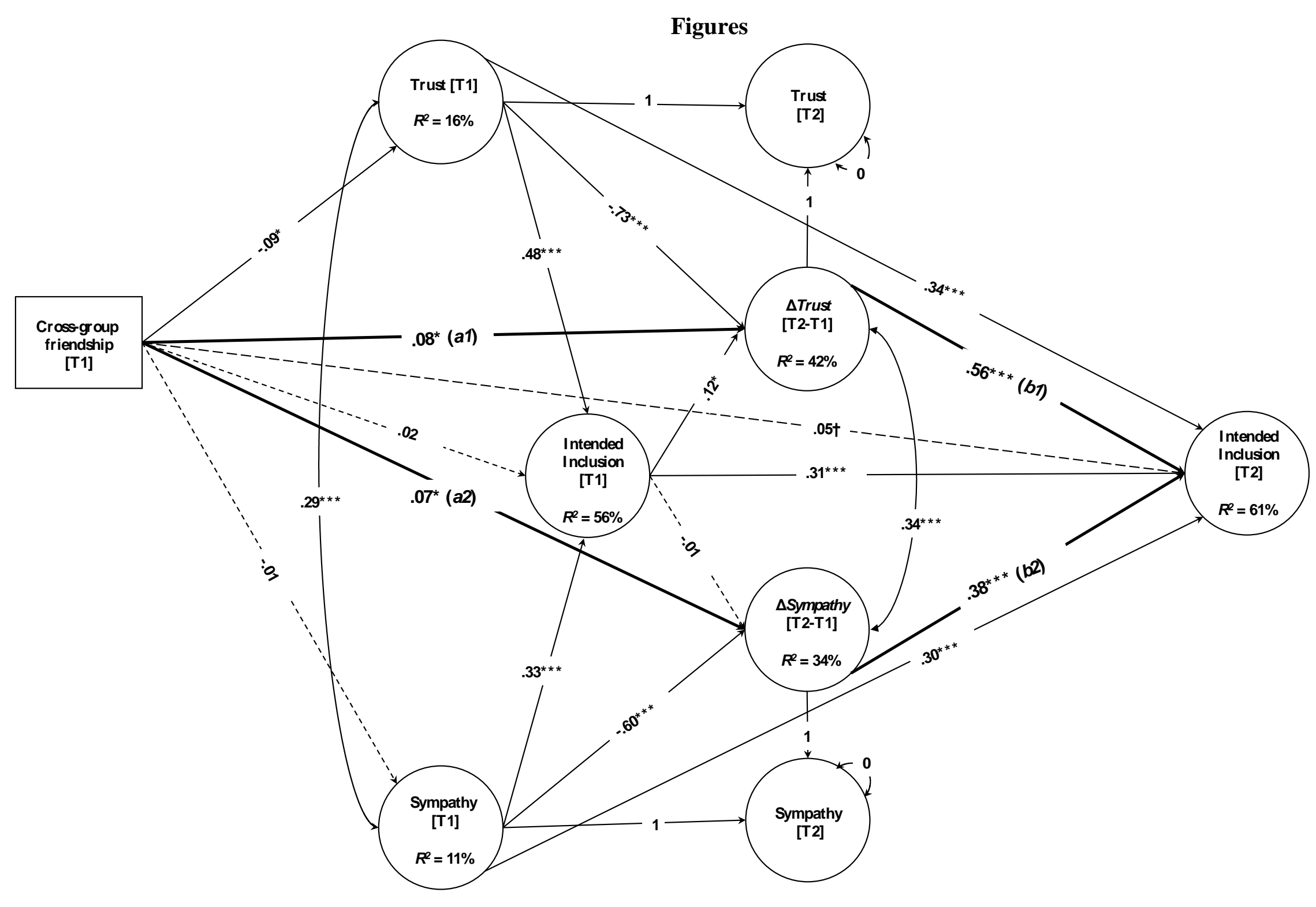


Figure 1. The relation between the number of cross-group friendships, intergroup trust, intergroup sympathy and attitudes towards inclusion; non-significant paths are shown by dashed arrows and standardized estimates are reported on the straight and curved arrows; in order to ease the interpretation of the figure, the items of the latent variables and their standard errors have been removed (a detailed report of the unstandardized factor loadings can be found in the online appendix S2-B); $\uparrow p<.10, * p<.05$, *** $p<.001$, two-tailed. 